Correction

\title{
Correction: Doke, R., et al. Very Local Subsidence near the Hot Spring Region in Hakone Volcano, Japan, Inferred from InSAR Time Series Analysis of ALOS/PALSAR Data. Remote Sens. 2020, 12, 2842
}

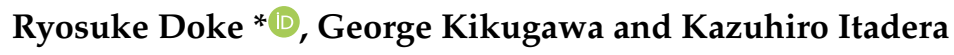

Hot Springs Research Institute of Kanagawa Prefecture, 586 Iriuda, Odawara 250-0031, Japan; kikugawa@onken.odawara.kanagawa.jp (G.K.); itadera@onken.odawara.kanagawa.jp (K.I.)

* Correspondence: r-doke@onken.odawara.kanagawa.jp; Tel.: +81-465-233-588

The authors wish to make the following corrections to this paper [1].

1. Correction of Equation

Equation (5)

$$
\left(\begin{array}{ll}
V_{Q E} & V_{Q U}
\end{array}\right)=\left(\begin{array}{ll}
V_{A} & V_{D}
\end{array}\right)\left(\begin{array}{cc}
\cos \theta_{A} & \sin \theta_{A} \\
\cos \theta_{D} & \sin \theta_{D}
\end{array}\right)
$$

should be replaced with

$$
\left(\begin{array}{ll}
V_{A} & V_{D}
\end{array}\right)=\left(\begin{array}{ll}
V_{Q E} & V_{Q U}
\end{array}\right)\left(\begin{array}{cc}
\cos \theta_{A} & \cos \theta_{D} \\
\sin \theta_{A} & \sin \theta_{D}
\end{array}\right)
$$

2. Corrections of Figures

Because of the correction of Equation (5), the following figures should be replaced from originals.

Graphical Abstract

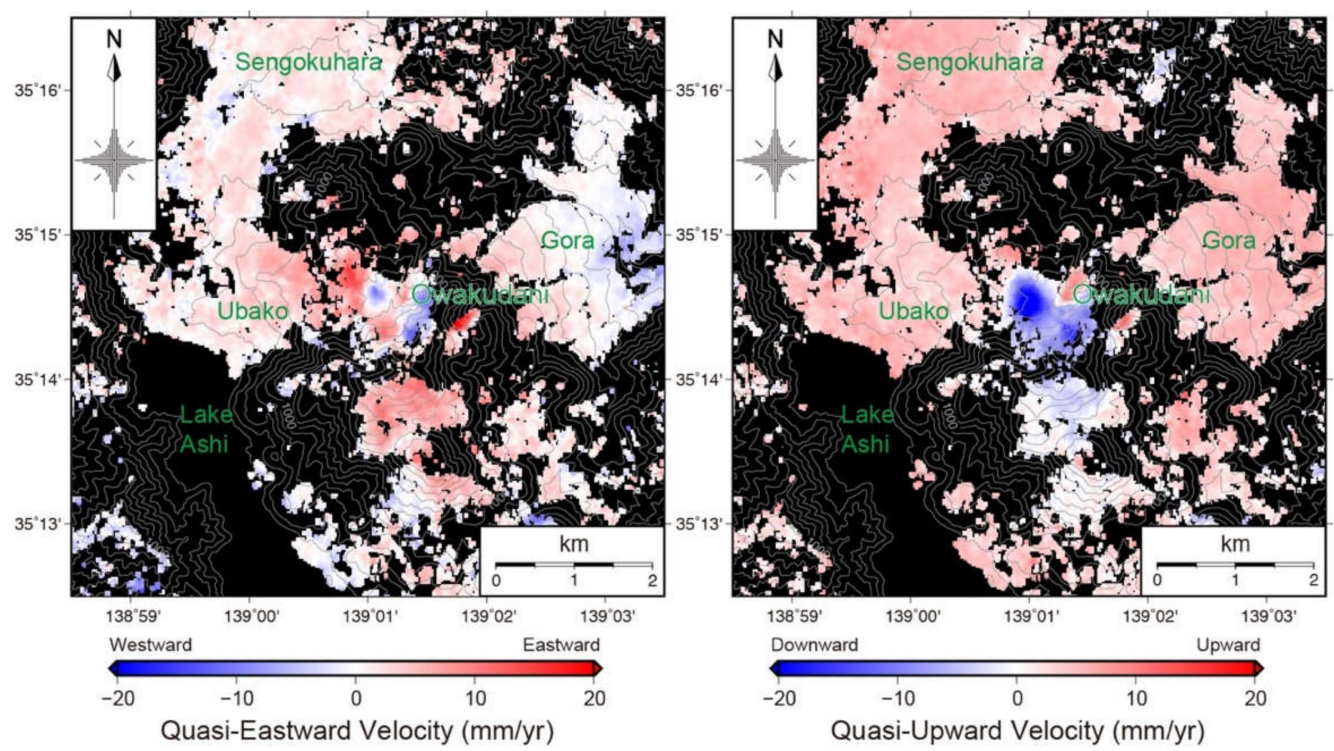


Figure 7

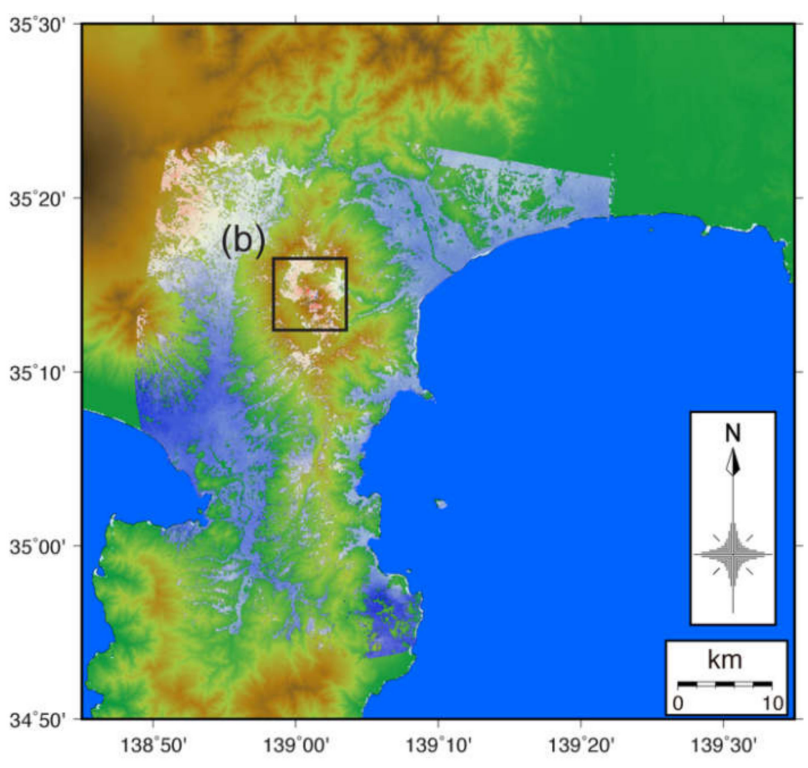

(a)

Figure 8

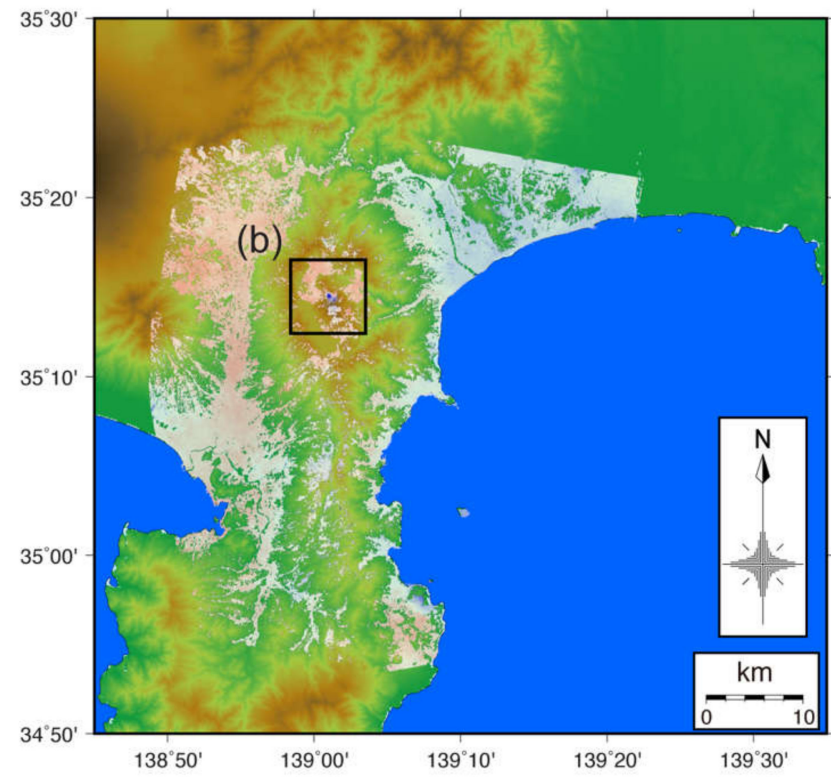

(a)

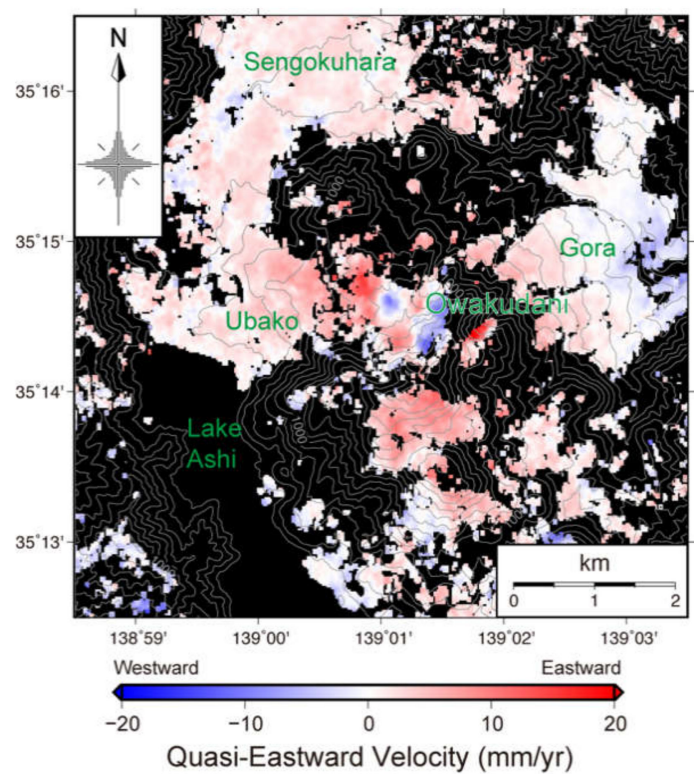

(b)

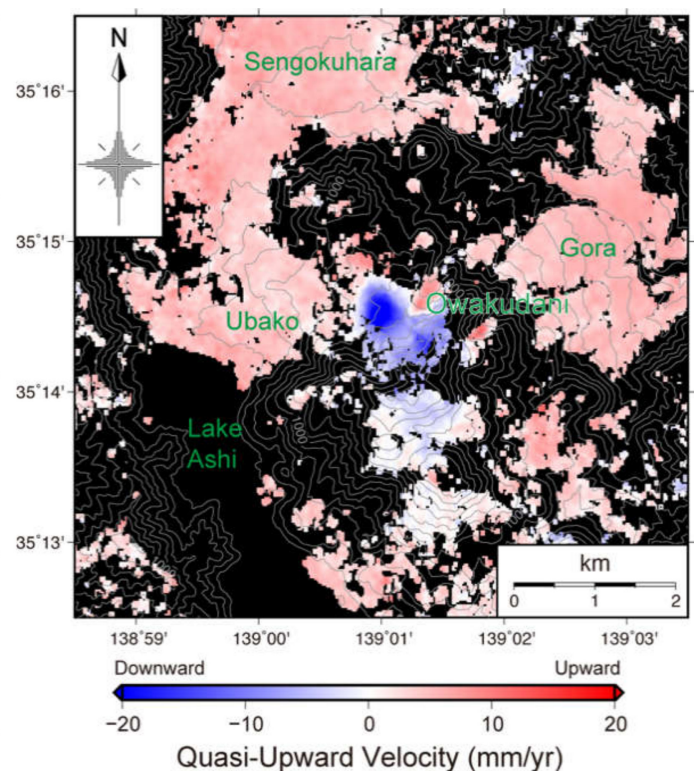

(b) 
Figure 12

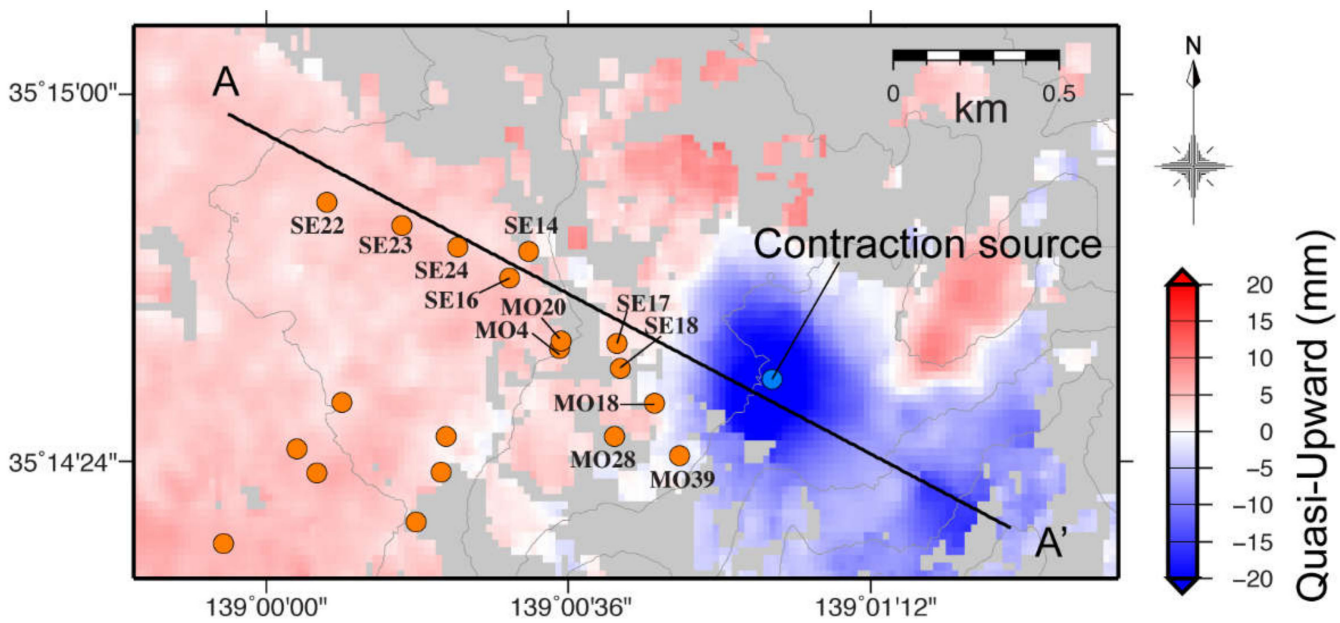

(a)

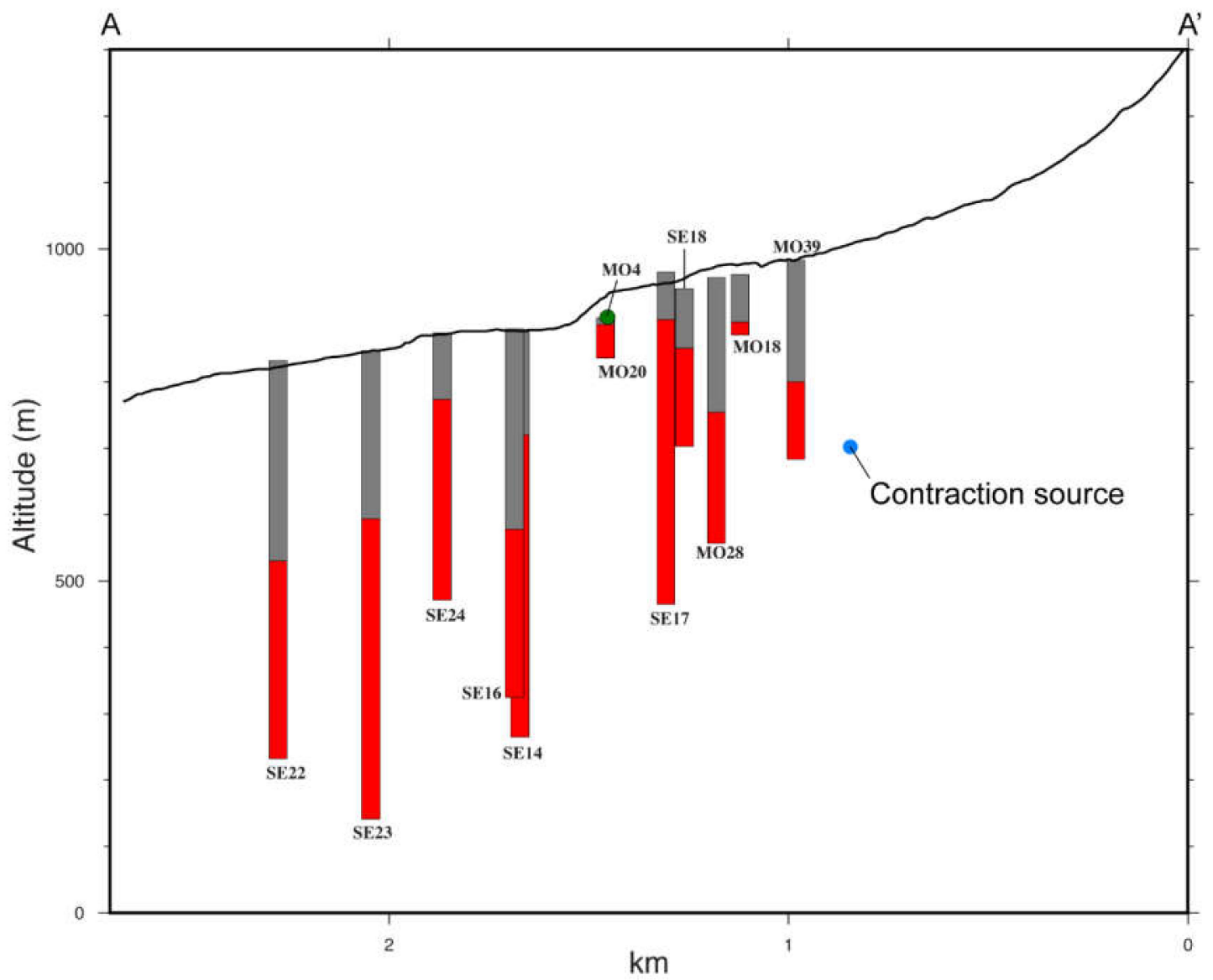

(b)

\section{Corrections in Abstract and Main Text}

Because of the correction of Equation (5), the estimated maximum subsidence rate should be replaced from "30 mm/year" to "25 mm/year." The subsidence rate was mentioned in:

- Abstract

- Last paragraph in "3.3. 2.5-D analysis" 
- First paragraph in "5. Conclusions"

The attitude of the LOS plane mentioned in the second paragraph of "3.3. 2.5-D analysis" should be replaced from "approximately $271^{\circ}$ and $85^{\circ}$ " to "approximately $269^{\circ}$ and $85^{\circ}$."

The authors would like to apologize for any inconvenience caused to the readers by these changes.

\section{Reference}

1. Doke, R.; Kikugawa, G.; Itadera, K. Very Local Subsidence Near the Hot Spring Region in Hakone Volcano, Japan, Inferred from InSAR Time Series Analysis of ALOS/PALSAR Data. Remote Sens. 2020, 12, 2842. [CrossRef]

Publisher's Note: MDPI stays neutral with regard to jurisdictional claims in published maps and institutional affiliations.

(C) 2020 by the authors. Licensee MDPI, Basel, Switzerland. This article is an open access article distributed under the terms and conditions of the Creative Commons Attribution

(CC BY) license (http://creativecommons.org/licenses/by/4.0/). 